\section{Nhanderekô Eg Kanhró: o audiovisual ampliando a visibilidade das escolas indígenas do Paraná}

\author{
Wagner Roberto do Amaral \\ wramaral2011@hotmail.com \\ Mônica Panis Kaseker \\ mkaseker@gmail.com \\ Universidade Estadual de Londrina, Brasil.
}

RECEPCIÓN: 26/04/19

ACEPTACIÓN FINAL: 30/05/19

\section{Resumo}

O artigo relata a experiência do projeto de extensão "Entre os saberes da escola indígena e da universidade: a comunicação audiovisual como elemento de expressão, articulação e fortalecimento da organização dos professores indígenas". Batizado com o nome indígena Nhanderekô Eg Kanhró, nas línguas Guarani e Kaingang, o projeto reflete sobre o "nosso jeito" de educar nas escolas indígenas ao referir-se aos processos educativos próprios do povo Kaingang e Guarani. Propõe-se o uso da produção audiovisual como estratégia de expressão, articulação e fortalecimento das especificidades da escola indígena conectando e ampliando territórios A metodologia das oficinas colaborativas de produção audiovisual e rodas de conversa é inspirada nas ideias de Paulo Freire (1985) e na experiência do projeto Vídeo nas Aldeias (Araújo, 2015; Pinhanta, 2019). Para a produção científica, nos baseamos na noção de participação observante de Wacquant (2002).

Palavras-chave: comunicação audiovisual, educação escolar indígena, identidade, interculturalidade.
Cultura(s) en clave de extensión universitaria / Intervenciones
Nhanderekô Eg Kanhró: audiovisual expanding visibility of indigenous schools of Parana

\section{Abstract}

This article is an experience report on the extension project "Between the knowledge of the indigenous school and the university: audiovisual communication as an element of expression, articulation and strengthening of indigenous teachers". Nicknamed Nhanderekô Eg Kanhró, in the Guarani and Kaingang languages, the project reflects on the "our way" of educating in indigenous schools. It is proposed to use audiovisual production as a strategy for expression, articulation and strengthening of the specificities of the Indigenous School, connecting and expanding territories. The methodology includes collaborative workshops of audiovisual production and chats, inspired by the ideas of Paulo Freire (1985) and the experience of the Video nas Aldeias (Araújo, 2015; Pinhanta, 2019). We are based on the notion of observing participation of Wacquant (2002)

Keywords: audiovisual communication, indigenous school education, identity, interculturality.
Nhanderekô Eg Kanhró: el audiovisual ampliando la visibilidad de las escuelas indígenas de Paraná

\section{Resumen}

El artículo relata la experiencia del proyecto de extensión "Entre los saberes de la escuela indígena y de la universidad: la comunicación audiovisual como elemento de expresión, articulación y fortalecimiento de la organización de los profesores indígenas". Con el nombre indígena Nhanderekô Eg Kanhró, en Guaraní y Kaingang, el proyecto refleja sobre la "nuestra manera" de educar en las escuelas indígenas. Se propone el uso de la producción audiovisual como estrategia de expresión, articulación y fortalecimiento de las especificidades de la Escuela Indígena de manera de conectar y ampliar territorios. La metodología de los talleres colaborativos de producción audiovisual y ruedas de conversación se inspira en las ideas de Paulo Freire (1985) y la experiencia del proyecto Vídeo en las Aldeas (Araújo, 2015; Pinhanta 2019). Para la producción científica, nos basamos en la noción de participación observante de Wacquant (2002)

Palabras clave: comunicación audiovisual, educación escolar indígena, identidad, interculturalidad.

Para citación de este artículo: Amaral, W.R. do, y Kaseker, M.P. (2019). Nhanderekô Eg Kanhró: o audiovisual ampliando a visibilidade das escolas indígenas do Paraná.+E: Revista de Extensión Universitaria, 9(10), 96-107. doi: 10.14409/extension.v9i10.Ene-Jun.8319. 


\section{Introdução}

O projeto "Entre os saberes da escola indígena e da universidade: a comunicação audiovisual como elemento de expressão, articulação e fortalecimento da organização dos professores indígenas - Nhanderekô Eg Kanhró" surgiu pelas necessidades socioeducativas identificadas junto aos professores indígenas, gestores das escolas estaduais indígenas e caciques das terras indígenas da região norte do Paraná. Essas demandas foram mapeadas ao longo de ações extensionistas desenvolvidas durante quatro anos por equipes da Universidade Estadual de Londrina (UEL).

O processo de estadualização das escolas indígenas no Paraná, iniciado por meio do Parecer CEB/CEE n. 423/2007, reconhece a contratação e atuação de professores indígenas bilíngues nas escolas indígenas. No entanto, a Rede Estadual de Educação do Paraná tem percebido a necessidade de acompanhamento permanente e de formação continuada dos professores indígenas, ainda não suprida pelo Estado, no sentido de qualificar a escolarização das crianças e jovens Kaingang, Guarani e Xetá.

O reconhecimento dos professores indígenas bilíngues no Brasil também é recente. Isso ocorreu a partir da Lei de Diretrizes e Bases da Educação Nacional (LDBEN) de 1996 e das Diretrizes Curriculares Nacionais da Educação Escolar Indígena (Parecer CNE/CEB n. ${ }^{\circ}$ 14/1999, posteriormente atualizado pelo Parecer $n^{\circ}$. 13/2012).

Um diagnóstico socioeducacional desenvolvido junto a essas escolas encontrou fragilidades identificadas no uso cotidiano das línguas Kaingang e Guarani, decorrente de processos progressivos de desprestígio e desvalorização das línguas indígenas, refletidas em sua organização escolar e curricular. Essas escolas vêm ampliando sua oferta de ensino fundamental e de ensino médio, apesar das dificuldades na reorganização da gestão e na sua proposta curricular, principalmente porque, até recentemente, os professores indígenas ainda eram minoria em suas equipes.

Observam-se ainda fragilidades na relação entre as equipes das escolas estaduais indígenas com os caciques e lideranças indígenas, inviabilizando a avaliação e elaboração de propostas curriculares na perspectiva de se fortalecer as políticas linguísticas em cada comunidade. Uma das questões diagnosticadas em ações extensionistas realizadas anteriormente foi sobre a presença de acadêmicos indígenas dessas comunidades vinculados aos cursos de licenciatura na Universidade Estadual de Londrina (UEL), na Universidade Estadual de Maringá (UEM) e na Universidade Estadual do Norte do Paraná (UENP) e que demandariam fortalecer sua presença e atuação nas escolas de suas aldeias. Constatou-se que havia a necessidade de articulação dos acadêmicos indígenas com as equipes pedagógicas das escolas indígenas e com as lideranças de suas comunidades, contribuindo na integração da educação superior com a educação básica, por meio do diálogo possível entre os conhecimentos acadêmicos, os conhecimentos escolares e os conhecimentos tradicionais indígenas (Amaral, 2016).

Nesse sentido, o projeto Nhanderekô Eg Kanhró desenvolve ações de sistematização e produção de material de apoio pedagógico com os professores e gestores indígenas numa perspectiva crítica, bilíngue e intercultural, bem como para o fortalecimento de uma rede permanente das escolas indígenas dessa região. Entre essas ações, estão previstas práticas comunicativas que ajudem na articulação e integração cultural entre os saberes da escola indígena e da universidade, como o uso do audiovisual. 
A comunicação audiovisual consiste numa forma eficaz diante da forte vocação oral dos povos indígenas, especialmente porque a capacidade expressiva das imagens engloba aspectos fundamentais da comunicação indígena: a oralidade e a corporalidade.

Neste artigo, a proposta é refletir sobre o uso da comunicação audiovisual como estratégia de resistência e desenvolvimento da educação escolar indígena. Busca-se analisar como o audiovisual pode colaborar para o fortalecimento dos jovens indígenas estudantes do ensino médio, dos acadêmicos da educação superior, dos professores indígenas e das lideranças indígenas. A ideia é propor uma metodologia de utilização da comunicação audiovisual que possa dar visibilidade às expectativas, intenções e desejos da comunidade escolar indígena acerca da escola que querem construir e da universidade que desejam acessar.

A metodologia para a produção científica a respeito das atividades extensionistas definese como participação observante, nos termos de Loïc Wacquant (2002), visto que a equipe participa da produção dos vídeos e é composta, em parte, por estudantes indígenas que viveram em algumas dessas comunidades, e em parte por estudantes e pesquisadores não indígenas. Assim, os observadores que descrevem estão inseridos no contexto observado. O observador torna-se um experimentador e a experimentação uma forma de observação. A equipe é composta por dois professores, sendo um do Serviço Social e outra da Comunicação, dois mestrandos em Comunicação e quatro estudantes de graduação das áreas de Jornalismo, Letras e Ciências Sociais, sendo três destes indígenas, dois Kaingang e um Guarani.

\section{O percurso da extensão comunitária junto às terras indígenas no norte do Paraná}

O projeto "Nhanderekô Eg Kanhró - entre os saberes da escola indígena e da universidade: a comunicação audiovisual como elemento de expressão, articulação e fortalecimento da organização dos professores indígenas", é resultado de uma sequência de ações extensionistas desenvolvidas desde o ano de 2013, pela UEL, junto às terras indígenas localizadas na região norte do Paraná.

A demanda por ações extensionistas junto a essas comunidades se apresentou na medida em que a Comissão Universidade para os Índios (CUIA) da UEL ${ }^{1}$ passou a diagnosticar as fragilidades educacionais dos acadêmicos indígenas ingressantes nesta instituição, exigindo ações voltadas à formação de professores indígenas e não indígenas nas escolas estaduais indígenas na região norte do estado do Paraná.

Um grupo de professores vinculados à CUIA elaborou um projeto de extensão a partir de edital do Programa Universidade Sem Fronteiras (USF), sendo este um programa de financiamento de ações extensionistas para as universidades estaduais paranaenses da Secretaria de Estado de Ciência, Tecnologia e Ensino Superior do Paraná (SETI-PR). O projeto então aprovado foi denominado "A Escola Indígena e seu Currículo: lugar da pertença e das identidades", com vigência do mês de julho de 2013 a junho de 2014. Contou com uma equipe de bolsistas, sendo: um profissional indígena recém-formado e cinco estudantes de graduação. O projeto elaborou um diagnóstico da educação escolar indígena e das escolas indígenas nas seis terras indígenas da região norte do Paraná, por meio de trabalho etnográ-

1) Para saber mais sobre a CUIA, acessar: http://flacso.org.br/files/2016/09/Universidade-para-Indigenas-GEA-Estudos_8-web.pdf 
fico em cada uma dessas comunidades e duas oficinas de formação continuada para os professores indígenas e não indígenas, além da presença de caciques e lideranças. Tais oficinas objetivaram apresentar os aspectos de potencialidade e de contradições identificados em cada uma das comunidades no que se refere aos aspectos do bilinguismo, da organização curricular e da gestão das escolas indígenas. Um dos aspectos identificados foi a presença subalternizada e silenciosa dos professores indígenas nas escolas indígenas diante do significativo numero de professores e diretores não indígenas que atuavam nesses espaços.

Na sequência, a equipe do Projeto apresenta novo projeto de extensão à SETI-PR por meio de novo edital pelo Programa USF, tendo sua aprovação. O projeto foi denominado "Bilinguismo, currículo e formação de professores e gestores das escolas indígenas do norte do Paraná", com vigência no período dezembro de 2015 a dezembro de 2016, contando com uma equipe bolsista de dois profissionais recém-formados e um estudante de graduação. Tendo em vista os apontamentos levantados pela edição anterior do projeto, o novo foco da ação foi o fortalecimento e a articulação dos professores e gestores indígenas das escolas indígenas por meio de cinco oficinas formativas realizadas nas dependências da UEL, contando com a logística de deslocamento e alimentação de todos os professores das seis terras indígenas com veículos desta universidade. As oficinas versaram com maior profundidade acerca das experiências de educação bilíngue realizadas nas escolas indígenas, assim como acerca das experiências de organização curricular e de organização escolar desenvolvidas e desejadas pelos professores indígenas e suas comunidades, contudo, nem sempre efetivadas dada a presença majoritária de professores não indígenas, todos eles com contratos precários e temporários com o Estado. Também foram trabalhados aspectos da legislação educacional no Brasil e da educação escolar indígena como modalidade educacional. O projeto se encerrou culminando na realização do um I Encontro Regional das Escolas Indígenas do norte do Paraná que, além de possibilitar o intercâmbio de experiências com pesquisadores indígenas de outras regiões do país, possibilitou a constituição da Comissão de Articulação dos Direitos das Escolas Indígenas do Norte do Paraná (CADEINP), assim batizada inicialmente pelos professores indígenas e, mais recentemente, passou a ser denominada Comissão de Articulação dos Direitos das Escolas Indígenas do Paraná. Cabe destacar que, das 39 escolas estaduais indígenas em funcionamento na ocasião no estado do Paraná, somente duas delas tinham diretores indígenas, sendo os dois diretores vinculados às escolas indígenas da região norte do Paraná.

A terceira edição do projeto de extensão teve vigência no período de abril de 2017 a abril de 2018, sendo denominado "A formação de gestores e professores da escola indígena bilíngue, diferenciada e intercultural e suas narrativas curriculares de resistência", contando com uma equipe bolsista formada por uma profissional indígena recém-formada e quatro estudantes de graduação, sendo um deles também indígena. Os objetivos desta edição do projeto se voltaram à qualificação e fortalecimento dos membros da CADEINP e à sistematização e produção do material de apoio pedagógico acerca da realidade das escolas indígenas do norte do Paraná. Também foi objeto de trabalho desta equipe o início da elaboração de uma pagina virtual para dar visibilidade às escolas estaduais indígenas e à CADEINP. Para tal, foram realizadas quatro oficinas de sistematização e de produção de material de apoio pedagógico intercultural e bilíngue no formato de uma Coletânea Temática de Educação Escolar Indígena voltada à formação dos professores indígenas e gestores das 
escolas indígenas, contando com a participação dos membros da CADEINP. A equipe do projeto também garantiu a participação dos professores indígenas da região norte do Paraná em todas as pré-conferências locais de Educação Escolar Indígena realizadas nas terras indígenas dessa região, por meio de transporte da UEL, contribuindo na sistematização das discussões e proposições.

A quarta edição do projeto, objeto deste artigo, denominada "Entre os saberes da escola indígena e da universidade: a comunicação audiovisual como elemento de expressão, articulação e fortalecimento da organização dos professores indígenas", em vigência no período de outubro de 2018 a setembro de 2019, conta com uma equipe composta por um profissional recém-formado e quatro bolsistas de graduação, sendo três deles indígenas. O projeto avança no sentido de garantir a vinculação de um número maior de acadêmicos indígenas nesta ação, possibilitando que os mesmos vivenciem seu duplo pertencimento (Amaral, 2010) por meio desta ação, se reconhecendo e se afirmando indígenas e, ao mesmo tempo, acadêmicos, neste caso, extensionistas em suas comunidades de pertencimento. Certamente por isso e por seu amadurecimento junto às comunidades indígenas que vêm sendo sujeitos desse processo, passa a ser batizado com um nome indígena que permite a confluência de expressões de duas línguas indígenas distintas - a Kaingang e Guarani - sinal de interculturalidade entre estes sujeitos e da própria universidade. Portanto, Nhanderekô Eg Kanhró representa o desejo e a intenção desta equipe em interculturalizar a extensão universitária com a afirmativa presença indígena na universidade.

\section{Com uma câmera na mão: a oralidade revisitada}

Um trabalho de referência no Brasil quanto à produção audiovisual em comunidades indígenas é o projeto Vídeo nas Aldeias (VNA), do indigenista Vincent Carelli. Desde 1997, o projeto passou a oferecer oficinas de produção audiovisual aos indígenas para que eles mesmos retratassem a realidade em suas comunidades. Em favor da identidade indígena, reconhecimento e manutenção dos costumes tradicionais e luta pelos territórios, o projeto foi pioneiro em trazer à tona a discussão no âmbito da comunicação, colocando em pauta a discussão sobre as realidades e as especificidades das mais diversas etnias existentes no país. Ainda que Vincent, idealizador do projeto, não fosse indígena - o que denota um movimento externo à realidade dos povos originários -, a dinâmica do processo de produção audiovisual se deu de forma endógena, com os próprios indígenas atuando na produção de suas narrativas (Araújo, 2015).

Em uma das edições, o professor indígena e realizador formado pelo projeto, Isaac $\mathrm{Pi}$ nhanta, da etnia Ashaninka, comenta sobre esse processo: "Se o vídeo vem ajudar a gente a se organizar, se ele traz alguma mudança, somos nós que estamos mudando, não é ninguém que vem de lá de fora. Alguém pode vir só nos orientar como usar, mas quem vai usar esses instrumentos somos nós. E se houver alguma mudança, somos nós mesmos que estamos fazendo ela acontecer. Então a gente quer entender tudo isso, a gente quer entender esse processo, porque a gente só vai se defender quando entender esse processo e esses instrumentos. O computador, a escrita, a tv e o vídeo são instrumentos ideais para aprofundar o nosso conhecimento" (Pinhanta, 2019:1). 
A forte ligação com a oralidade e corporalidade permite ao audiovisual uma afinidade com as culturas indígenas. "Sem a intermediação da escrita, com a produção audiovisual esses povos passam da linguagem oral diretamente para a audiovisual, incitando mudanças na posição (de receptores a produtores), na forma (de documentários etnográficos a estilos variados de produção audiovisual) e no conteúdo (de 'índios puros' projetados pela sociedade nacional a 'sujeitos reais', os quais narram suas culturas)" (Pereira, 2010:1). A autorrepresentação é importante para que os indígenas se apropriem e interajam com as tecnologias cognitivas, transformando o modo como eles se veem e são vistos. Esse método desenvolve ainda a autoconsciência de como se constroem o imaginário e a memória do que é ser indígena.

Outro exemplo, mais recente, mas que é muito análogo à proposta do VNA, é a experiência da Rádio Yandê, a primeira rádio online indígena do Brasil, a partir de 2013, atuando não apenas como um canal de informação sobre as pautas indígenas atuais, mas também no sentido de comunicar (admitindo o significado de partilhar o conhecimento) as comunidades indígenas. A Yandê compartilha produções, inclusive audiovisuais, de diversas etnias do Brasil que se apropriam da comunicação para compartilhar seus conhecimentos tradicionais e resistir como indígenas dentro de uma sociedade repleta de preconceitos e ideias colonizadas a respeito do que é ser indígena (Ribeiro, 2017, 2018). A web rádio tem o intuito de partilhar seus conteúdos entre as comunidades, criando assim uma rede de conhecimentos entre as etnias, mas, sobretudo, de descolonizar a imagem estereotipada dos povos indígenas.

A partir desses exemplos, que se somam a vários outros que estão atuantes nos mais diversos canais de comunicação (especialmente canais online), as comunidades indígenas têm compreendido a importância de se apropriarem de aparatos tecnológicos e criarem suas próprias narrativas, em um movimento endógeno, a partir de um olhar étnico-comunitário. Dessa forma, as narrativas produzidas pelos próprios indígenas admitem um caráter diferenciado do que é proposto e noticiado pela mídia hegemônica, uma vez que contam a partir de si mesmos e de seus territórios.

A apropriação da comunicação audiovisual por parte das comunidades indígenas vinculadas ao Projeto Nhanderekô Eg Kanhró necessita, antes de tudo, englobar a compreensão das relações sociais produzidas dentro dos territórios indígenas através da educação escolar indígena. Uma escola em território indígena tem o dever de articular a formação das crianças, jovens e adultos nos parâmetros da educação básica, mas, fundamentalmente, para a afirmação e fortalecimento da identidade indígena - neste caso, Kaingang e Guarani -, articulando os conhecimentos escolares com os conhecimentos tradicionais ou mesmo encharcando e interculturalizando a educação escolar e a escola dos saberes indígenas.

Desta forma, a presença de professores e pedagogos indígenas à frente da educação escolar indígena é imprescindível para a autonomia pedagógica junto às especificidades da cultura e dos costumes tradicionais. De acordo com a Constituição Federal Brasileira de 1988, a educação escolar indígena tem o intuito de manter uma escola específica, bilíngue, intercultural, diferenciada e comunitária, porém, a realidade é diferente. Segundo dados coletados pelos integrantes do projeto "Entre os saberes da escola indígena e da universidade: a comunicação audiovisual como elemento de expressão, articulação e fortalecimento da organização dos professores indígenas - Nhanderekô Eg Kanhró", 44\% dos professores das nove escolas do norte do Estado do Paraná não são indígenas. Esses números levam à 
reflexão de que a educação escolar indígena enfrenta alguns problemas no que diz respeito ao cumprimento da Lei de Diretrizes e Bases da Educação Nacional (LDBEN). ${ }^{2}$

Para isso, a formação específica de professores indígenas nas mais variadas áreas do conhecimento a fim de, principalmente, aplicá-los na educação escolar básica indígena é imprescindível, uma vez que os limites da escola indígena não se dão pelos seus muros ou cercas, mas se compreende em toda a extensão da aldeia indígena, denotando uma vivência em comunidade para o compartilhamento do saber. Desta forma, a escola se localiza no quintal da aldeia, esta nela territorializada.

Mas também, algumas experiências na área da comunicação por parte das comunidades indígenas mostram que o compartilhamento do saber tem tomado outras dimensões e que as comunidades indígenas buscam atualizar seus processos educativos através da comunicação. Com a utilização de aparatos tecnológicos, organização em redes sociais, apropriação dos meios e canais de comunicação, as comunidades indígenas têm a oportunidade de expandir seus conhecimentos e seus territórios a outros grupos étnicos, garantindo mobilização e apoio, além das sociedades não indígenas.

Outro ponto a se considerar no que concerne à apropriação da comunicação pelas comunidades indígenas, levando em conta a experiência do projeto Nhanderekô Eg Kanhró da UEL, é a contribuição que a comunicação agrega à educação. A partir da utilização do audiovisual, aspira-se que as etnias Kaingang e Guarani que participam do projeto, tenham a oportunidade de elaborar narrativas sobre a escola indígena que desejam. As rodas de conversa têm como proposta organizar o pensamento comunitário dos educadores das diversas escolas e, ao gravá-las em um vídeo que possa ser apresentado aos novos integrantes da escola, sirva de guia para alinhar essa construção coletiva. Ainda, o audiovisual "dá a possibilidade da história e da língua de seu povo ficarem guardadas para sempre" (Di Felice; Pereira, 2017:52), uma vez que a "capacidade expressiva das imagens engloba alguns dos componentes fundamentais da comunicação indígena: a oralidade e a corporalidade" (Di Felice; Pereira, 2017:53).

As imagens tomadas pelos indígenas em suas narrativas admitem uma dimensão não apenas de demarcação do local que está sendo descrito nos vídeos, mas também assume o papel de contextualizar a identidade étnica e a relação da comunidade com o espaço geográfico, dando margem a um novo tipo de educação aos povos indígenas, uma educação pautada no poder da comunicação para sua presença nas redes digitais, permitindo maior diálogo com as demais esferas da sociedade em um movimento intercultural. Importa ainda que eles protagonizem esse processo, imprimindo seu olhar, seu ponto de vista sobre as realidades a serem observadas e registradas.

As relações a serem estabelecidas entre os sujeitos educadores, educandos e lideranças indígenas, a partir da comunicação audiovisual e de outros meios de comunicação, que constituem uma rede intercultural de saberes, pode dar a dimensão de um novo habitar ${ }^{3}$ que "não se restringe ao residir ou apenas ao estar" (Franco, 2017:93), mas também pode ser entendido como construir, refletir e afirmar relações identitárias para eles fundamentais.

2) A Lei No 9.394 garante o direito à educação intercultural, comunitária, específica e diferenciada, preservando os direitos conquistados na Constituição Federal de 1988 (CONEEI, 2016).

3) Este conceito é abordado em toda a obra de Di Felice e Pereira (2017) a partir do entendimento heideggeriano. 
Assim, tanto a educação escolar indígena quanto a apropriação da comunicação como instrumento de fortalecimento, manutenção e resistência das culturas indígenas se interligam e se fazem de extrema importância para a escola indígena, uma vez que proporcionam expandir as especificidades e as realidades das etnias em questão.

\section{Conhecendo as comunidades e as escolas}

O projeto atende seis terras indígenas da região norte do Paraná, onde estão instaladas nove escolas estaduais indígenas. Entre os professores que trabalham nessas escolas, os indígenas já são maioria, o que aconteceu no decorrer dos últimos cinco anos. Do total de 147 professores, 83 são indígenas (56,4 \%). No entanto, as funções de direção e de coordenação pedagógica ainda são ocupadas, em grande parte, por professores não indígenas. De nove diretores, somente dois são indígenas (22,2 \%) e dos 12 coordenadores pedagógicos, cinco são indígenas (41,6 \%).

As seis terras indígenas ficam a distâncias que variam entre 90 a 171 quilômetros de Londrina (onde está localizada a UEL). Nessas comunidades estudam, aproximadamente, mil crianças, jovens e adultos indígenas. A Terra Indígena (TI) Apucaraninha é a mais próxima e a que envolve o maior número de habitantes, em torno de 1420 pessoas, todas pertencentes à etnia Kaingang, segundo o último Censo nacional realizado em 2010 (IBGE, 2010). $O$ território, atualmente de 5574 hectares, é demarcado e possui três escolas, que atendem aproximadamente 550 estudantes, desde a educação infantil até o ensino médio bilíngue.

Na Terra Indígena de São Jerônimo, vivem aproximadamente 495 pessoas pertencentes a três etnias: Kaingang, Guarani e Xeta. O território, atualmente de 1339,34 hectares, tem um colégio estadual que atende a 262 alunos, desde a educação infantil até o ensino médio. A Terra Indígena Barão de Antonina possui 498 pessoas que habitam seus 3751 hectares. Duas escolas estaduais atendem cerca de 130 alunos.

A Terra Indígena Laranjinha, com território de mais de mil hectares, tem 184 habitantes da etnia Guarani Nhandewa. A escola possui 31 alunos matriculados nos anos iniciais do ensino fundamental. A Terra Indígena Ywy Porã, ou Posto Velho, está em processo de retomada há mais de 10 anos. Lá vivem cerca de 100 pessoas e há uma escola estadual com13 alunos matriculados até o quarto ano do ensino fundamental.

Já a Terra Indígena Pinhalzinho tem aproximadamente 129 pessoas vivendo em seu território de 593 hectares. Sua escola estadual atende a 37 alunos do ensino fundamental.

Algumas iniciativas chamam a atenção no que se refere ao desenvolvimento da educação escolar indígena nessas escolas. A escola estadual indígena Ywy Porã, da TI Pinhalzinho, liderada por um diretor Guarani, visa atender as especificidades da comunidade, com atividades educacionais voltadas para a cultura Guarani Nhandewa e fazendo correlações do conhecimento científico dos não indígenas aos saberes tradicionais da comunidade. Já na Terra Indígena Apucaraninha, a escola estadual indígena João Kavagtan Vergilho trabalha os conteúdos apenas na língua materna da comunidade, o Kaingang. E no Colégio estadual indígena Benedito Rokag, além de ter aulas de língua Kaingang, os alunos reuniram jovens da comunidade para formar um grupo de danças e cantigas tradicionais. Para além das danças e das cantigas, o grupo preserva ainda as marcas tribais Kaingang e algumas vestimentas tradicionais que são usadas durante as apresentações culturais. No calendário das duas 
escolas consta a festa do Pari, comemoração que busca reviver o ritual de pesca com armadilhas, tradicional da cultura Kaingang, aliado a danças, cantigas e comidas tradicionais. A festividade dura cerca de cinco dias. As demais escolas indígenas possuem disciplinas específicas das línguas maternas de suas comunidades.

\section{Formatando as oficinas de vídeo}

O projeto iniciado no ano de 2018 segue em desenvolvimento no contexto de apresentação desse texto. Durante cinco meses, a equipe composta por oito pessoas, num primeiro momento, estudou temas como a presença indígena na formação do Brasil, a legislação da educação escolar indígena no Brasil e no Paraná, as cosmologias e características identitárias das etnias Kaingang e Guarani, as representações midiáticas dos povos indígenas, as experiências de produção audiovisual como o projeto Vídeo nas Aldeias, dentre outros temas.

Num segundo momento, houve a primeira visita de apresentação da equipe às terras indígenas envolvidas no projeto - aos caciques e lideranças indígenas e às equipes das escolas indígenas. Entre os estudantes indígenas da UEL que compõem a equipe de bolsistas do projeto há uma acadêmica Guarani da TI de Barão de Antonina, um acadêmico Guarani da TI de Pinhalzinho e um acadêmico da etnia Funiô/Kaingang da TI de Apucaraninha, que auxiliaram nos contatos com as lideranças e professores das comunidades.

As oficinas foram voltadas para dois grupos distintos sendo: um grupo sendo constituído por professores e lideranças indígenas, e outro grupo a ser constituído por estudantes indígenas do ensino médio, que estudam nas escolas indígenas que ofereçam esse nível de ensino ou que estudam em escolas não indígenas do entorno das aldeias. Para a formatação das oficinas de vídeo, a equipe baseou-se nas ideias de Paulo Freire sobre a educação emancipadora, ao considerar que: "o conhecimento exige uma presença curiosa do sujeito em face do mundo. Requer sua ação transformadora sôbre a realidade. Demanda uma busca constante. Implica invenção e reinvenção" (Freire, 1985:16).

Por outro lado, as Oficinas inspiraram-se nos modos de vida dos próprios indígenas, que em geral, costumam trocar experiências e refletir juntos sobre o passado, o presente e as aspirações para o futuro. Essas trocas e transmissões do saber tradicional geralmente se dão pela oralidade. Nesse sentido, surgiu a ideia de iniciar as atividades da Oficina com uma roda de apresentação dos participantes e de conversa. Após as apresentações individuais, foi realizada a apresentação do projeto, mencionando aspectos legais da educação indígena e falando sobre os objetivos do vídeo a ser produzido, sendo o principal deles o de refletir sobre a "escola indígena que temos e a que queremos".

Em seguida, foi realizado o início da roda de conversa com os roteiros de questões problematizadoras elaborados pela equipe, distintos para cada grupo, seguindo eixos de reflexão para os quais são escolhidos relatores. Os eixos orientadores das oficinas foram os seguintes: bilinguismo, currículo, gestão e participação, liderança, memória da escola. Após selecionados os relatores, o grupo composto por professores, diretores, caciques e lideranças passa a conversar sobre as seguintes questões previamente propostas e outras que possam surgir no momento:

Como era a escola para os indígenas no passado?

Como é hoje? 
Como é a escola indígena na comunidade hoje?

O que a educação escolar indígena na comunidade tem de diferente?

Como é organizado o currículo?

Como é o ensino da língua Guarani/Kaingang (ou outras)?

Como é a escola (Guarani/Kaingang) que queremos para o futuro?

A escola Guarani/Kaingang tem o papel de formar lideranças? Como?

Como deve ser o professor da escola indígena?

E a gestão da escola indígena? Deve ser diferente das demais?

Para que serve a escola indígena?

Ao longo dessa roda de conversa, os relatores dos eixos propostos sintetizam os principais pontos de convergência nas ideias do grupo. Estas sínteses foram apresentadas ao final, quando cada relator anota as palavras-chaves em um quadro de papel afixado na parede. Os relatores contam o que concluíram, sintetizando cada ponto e essa fala é gravada em vídeo.

Paralelamente, a outra oficina realizada com os estudantes indígenas do ensino médio, seguiu-se uma dinâmica parecida. Na roda de conversa, foram apresentadas as perguntas guias:

Quais foram as maiores dificuldades para vocês na escola?

É importante estudar em escola indígena? Por quê?

Como deve ser uma escola indígena? Ela é diferente das outras?

Depois do ensino médio, o que você pretende fazer?

Vocês pensam em fazer universidade? Por quê?

Como vocês acham que é a universidade?

Ao final, os relatores socializaram o que concluíram, sintetizando cada ponto. Os relatos foram gravados com o uso de aparelhos celulares, motivando um participante gravar o outro. Ao final, foi apresentada a ideia de criar um canal da escola no YouTube, no qual os estudantes possam postar vídeos que atendam a finalidade de fortalecer a educação e suas identidades indígenas. Os vídeos feitos com aparelhos celulares foram copiados pela equipe para compor o documentário.

É importante mencionar que toda a produção obedece às exigências do Comitê de Ética em Pesquisas com Seres Humanos, o que inclui elaborar os Termos de Consentimento e solicitar a autorização de cada sujeito.

Para concluir o processo, foram gravadas imagens externas de cada terra indígena, com tomadas gerais da comunidade, a fachada e as instalações da escola, assim como tomadas das oficinas, das salas de aula durante as atividades escolares letivas.

Após essa etapa, o trabalho de edição tem sido realizado na universidade, com a participação dos estudantes indígenas que integram a equipe, seguindo as sugestões da comunidade escolar. Após uma primeira versão do vídeo, esperamos ter a oportunidade de discutir a edição com representantes das escolas participantes, bem como das lideranças indígenas, para então concluirmos a edição final do material. 


\section{Resultados e conclusões}

Percebe-se ao longo das quatro edições de projetos de extensão que houve avanços quanto à mobilização e articulação de professores, pedagogos e gestores escolares indígenas, porém, respeitando as temporalidades e dinâmicas dos envolvidos nesse processo, seja o tempo dos professores e lideranças indígenas, seja o tempo dos membros da CADEINP, seja o tempo institucional da SETI-PR em publicizar seus editais e autorizar o funcionamento dos projetos com orçamentos necessários para sua viabilidade. Essa articulação tem sido difícil e custosa, visto que o apoio governamental se apresenta frágil e insuficiente. Devido às distâncias entre as terras indígenas e a ausência de momentos de formação continuada que reúnam os professores indígenas pela Secretaria de Estado da Educação do Paraná (órgão responsável pela manutenção das escolas estaduais indígenas), a troca de experiências e a mobilização desses agentes se dá ainda de forma tímida. A expectativa não melhora diante da situação política e econômica do país. A educação escolar indígena se apresenta profundamente à margem das políticas educacionais no Brasil e no estado do Paraná.

Atualmente, as escolas indígenas atuam de forma desarticulada entre si. Entre as nove escolas, a da TI Pinhalzinho apresenta um Projeto Político Pedagógico (PPP) e currículo diferenciados, uma vez que os conteúdos aplicados em aula são voltados para os saberes tradicionais, mesmo quando se trata do conhecimento do não indígena. Constatamos que esse avanço ocorre pelo nível de organização desta comunidade indígena. Já as demais escolas apenas possuem um PPP diferenciado, focalizando no ensino das línguas indígenas, ainda que estas não sejam as línguas maternas nas comunidades: como é o caso da escola da TI São Jerônimo que oferece três línguas distintas para atender as três etnias presentes naquela comunidade. Na TI Apucaraninha, onde a língua materna é o Kaingang, o grupo de dança Nen Gã e a Festa do Pari são elementos fundamentais para cultivar os conhecimentos tradicionais e ressaltam ainda mais a importância de se atender as especificidades de cada povo na educação escolar indígena. O currículo escolar é diferenciado nesta comunidade, após negociação e conquista junto à Secretaria de Estado da Educação do Paraná (SEED). No entanto, há escolas que desconhecem essas iniciativas e acabam se atendo, com centralidade, ao modelo de educação escolar do não indígena.

A Comissão de Articulação dos Direitos das Escolas Indígenas do Paraná (CADEINP), que ainda está em processo de regulamentação, surgiu em 2017 diante da necessidade dos professores indígenas se articularem em defesa da manutenção e desenvolvimento da educação escolar indígena, ameaçada frequentemente por políticas governamentais. Acreditase que a realização das oficinas de audiovisual e da produção de vídeos sobre as escolas e sobre as características da educação indígena que as comunidades aspiram implantar possam colaborar para essa integração, no sentido de sintetizar as especificidades e demandas da educação escolar indígena dessas escolas. Por outro lado, espera-se que o audiovisual colabore na maior visibilidade da problemática educacional indígena e na sensibilização social sobre essa temática, assim como, nas palavras de Di Felice (2017), amplie os territórios indígenas nas redes digitais. 


\section{Referências bibliográficas}

Amaral, W.R. do (2010). As trajetórias dos estudantes indígenas nas Universidades Estaduais do Paraná: sujeitos e pertencimentos. Tese (Doutorado em Educação) - Universidade Federal do Paraná. Curitiba. Acessado em 25/04/2019, em: http://www.ppge.ufpr.br/teses\%20d2010/d2010_Wagner\%20Roberto\%20do\%20Amaral.pdf

(2016). Indígenas nas universidades estaduais do Paraná: sujeitos, trajetórias e pertencimentos. In Amaral, W.R. do; Fraga, L.; Rodrigues, I.C. (Orgs.). Universidade para indígenas: a experiência do Paraná. Rio de Janeiro: FLACSO, GEA; UERJ, LPP.

Amaral, W.R. do; Fraga, L.; Rodrigues, I.C. (Orgs.) (2016). Universidade para indígenas: a experiência do Paraná. Rio de Janeiro: FLACSO, GEA; UERJ, LPP. Acessado em 25/04/2019, em: http://flacso.org.br/files/2016/09/Universidade-para-Indigenas-GEA-Estudos_8-web.pdf

Araújo, J.J. de (2015). Cineastas indígenas, documentário e autoetnografia: um estudo do projeto Vídeo nas Aldeias. 2015. Tese (Doutorado em Multimeios) - Instituto de Artes da Unicamp. Universidade Estadual de Campinas, Campinas.

CONEEI (2016). // Conferência Nacional de Educação Escolar Indígena. Brasília: Ministério da Educação, Secretaria de Educação Continuada, Alfabetização, Diversidade e Inclusão (Secadi).

Di Felice, M. (2017). Atopia, redes digitais e a crise das formas do habitar do Ocidente. In Di Felice, M.; Pereira, E.S. (Orgs.). Redes e ecologias comunicativas indígenas: as contribuições dos povos originários à Teoria da Comunicação. São Paulo: Paulus.

Di Felice, M.; Pereira, E.S. (2017). Formas comunicativas do habitar indígena: a digitalização da floresta e o net-ativismo nativo no Brasil. In Di Felice, M.; Pereira, E.S. (Orgs.). Redes e ecologias comunicativas: as contribuições dos povos originários à Teoria da Comunicação. São Paulo: Paulus.

Franco, T.C. (2017). Redes de redes e a forma comunicativa do habitar Krahô. In Di Felice, M.; Pereira, E.S. (Orgs.). Redes e ecologias comunicativas: as contribuições dos povos originários à Teoria da Comunicação. São Paulo: Paulus.

Freire, P. (1985). Extensão ou Comunicação? São Paulo: Paz e Terra.

IBGE (2010). Censo Demográfico Populacional. Disponível em https://censo2010.ibge.gov.br/ (acesso em: 16 mar. 2019).

Pereira, Eliete S. (2010). Mídias nativas: a comunicação audiovisual indígena - o caso do Projeto Vídeo nas Aldeias. C-legenda, Revista do Programa de Pós-graduação em Cinema e Audiovisual da Universidade Federal Fluminense, Niterói, RJ, (23), 61-72. Disponível em: http://www.ciberlegenda.uff.br/index.php/revista/article/ view/133/49 (acesso em: 16 mar. 2019).

(2017). Ecologia da Comunicação das formas estéticas reticulares: notas sobre a arte Kaxinauá. In Di Felice, M.; Pereira, E.S. (Orgs.). Redes e ecologias comunicativas: as contribuições dos povos originários à Teoria da Comunicação. São Paulo: Paulus.

Pinhanta, Isaac. (2004). Você vê o mundo do outro e olha para o seu. Disponível em: http://www.videonasaldeias.org.br/2009/biblioteca.php?c=23 8 (acesso em: 16 mar. 2019).

Ribeiro, L.F. (2017). Webradio Yandê e a descolonização da mídia, 40 Congresso Brasileiro de Ciências da Comunicação - INTERCOM 2017, Curitiba. Anais eletrônicos... São Paulo: Intercom. Disponível em: http:// portalintercom.org.br/anais/nacional2017/resumos/R12-1867-1.pdf (acesso em: 16 mar. 2019).

(2018). A experiência da Webradio Yandê como etnomídia em um contexto de convergência midiática. $41^{\circ}$ Congresso Brasileiro de Ciências da Comunicação - INTERCOM 2017, Joinville. Anais eletrônicos... São Paulo: Intercom. Disponível em: http://portalintercom.org.br/anais/nacional2018/resumos/R13-1554-1.pdf (acesso em: 16 mar. 2019).

Wacquant, L. (2002). Corpo e Alma: notas etnográficas de um aprendiz de boxe. Rio de Janeiro: Relume Dumará. 